\title{
Burnout among chiropractic practitioners: real or imagined an exploratory study protocol
}

Shawn Williams ${ }^{1 *}$ and Stanley Innes ${ }^{2}$

\begin{abstract}
Burnout is a psychological syndrome of emotional exhaustion, depersonalization and reduced personal accomplishment that has been found to exist in a significant number of healthcare and helping professionals. It imposes a significant societal burden by shortened practitioner lifespan, decreased efficiency, negative health outcomes and poorer levels of patient care. Theoretical models suggest that it appears to be the result of a complex interaction between job resources and job demands. It may be reasonable to conclude that Chiropractic professionals experience similar vocational demands and thus experience significant levels of occupational stress and subsequent burnout. However the data on burnout within the chiropractic profession is limited. It is possible that this results in significant negative outcomes on chiropractors and their patients. Therefore, the objective of this paper is to demonstrate the need to explore burnout in chiropractic practice and offer a research protocol for a potential study.
\end{abstract}

Keywords: Burnout, Chiropractic, Exploratory

\section{Background}

Past research has sought to explore and quantify the elevated levels of stress and susceptibility to burnout found in the helping professions. This has been demonstrated in professionals that share many similar characteristics to chiropractic such as medical practitioners $[1,2]$, dentists [3-5], nurses [6-9], physical therapists [10-15], and occupational therapists [16-18]. However, this subject has never been studied in the chiropractic profession.

Factors that have been identified which increase levels of stress and susceptibility to burnout include constantly focusing on the needs of others, which may lead to fatigue, feelings of frustration and anger, a sense of ineffectiveness and failure, and the onset of depression and associated co-morbidities [2,19-22]. Other factors include physical workload, quality of recipient contact, physical environment, type of patient feedback, financial pressures and supervisor support [22]. These factors have been shown to vary across geographic locations [10-13,23].

\footnotetext{
* Correspondence: swilliams2@york.cuny.edu

'Department of Health Professions, CUNY York College, 94 - 20 Guy R.

Brewer Blvd, Jamaica, NY 11451, USA

Full list of author information is available at the end of the article
}

With this body of evidence available for comparison it would seem logical to explore those significant factors already identified. Therefore, the objective of this paper is to demonstrate the need to explore burnout in chiropractic practice and to propose a research protocol for a potential study. Thus we would seek to question a representative selection of chiropractors from varying locations on their perceptions of the impact of these factors using an established and validated questionnaire.

\section{Literature review}

In 2008 there were 49,100 registered chiropractors in the U.S.; of these approximately $44 \%$ were self-employed [24]. While there is a trend of increasing numbers of chiropractors there is counter pattern of declining use of chiropractic. In the U.S., 9.9\% of U.S. adults reported having seen a chiropractor in 1997 vs. 7.4\% in 2002. This was the largest relative decrease among CAM professions, which overall had a stable use rate [25].

Against this backdrop is the unfavourable public perception of chiropractic when compared with mainstream medicine with regard to ethics and honesty: in a 2006 Gallup Poll of U.S. adults, chiropractors were rated last among seven health care professions for being very high or high in honesty and ethical standards [26].

\section{Ciomed Central}


CareerCast.com rates chiropractic as the $10^{\text {th }}$ least stressful occupation in the USA in 2011 [27]. They based this on their perception that chiropractic involves low levels of physical demands, healthy offices, low levels of required stamina, low levels of competitiveness, no travel, few deadlines, no personal hazards, solid levels of income, and a positive outlook for employment and income growth. No significant sampling of chiropractors was undertaken in obtaining these results.

This perception would stand in contrast to a retrospective analysis [28] of licensed chiropractors in California. Here, alarmingly, the authors identified that the attrition in the first 10 years of practice rose from $10 \%$ to $25 \%$ in the past decade. The authors hypothesized that the rising attrition rate of chiropractors may be linked to a number of forces such as changes in population, an oversupply of chiropractors, changes in reimbursement, the cost of education, and chiropractors' general dissatisfaction with their own profession [28]. In addition, data from a recent pilot study [29] exploring the attitudes of non-practicing chiropractors suggest that business ethics, overhead expenses and salaries were contributing factors of attrition in the chiropractic profession.

A cursory glance on affiliated contemporary chiropractic material suggests that stress and burnout are salient and important issues. The first discussion on burnout was noted in 1987 in an ICA Review of Chiropractic [30]. Shelley Simon also wrote of this syndrome and its likely increasing prevalence in the Chiropractic newspaper Dynamic Chiropractic [31]. More recently it was raised in the American Chiropractors Association News [32] as an occupation whose practitioners are more prone to job burnout. A web search reveals a multitude of chiropractic associated organizations/assistants offering to help reduce stress levels by altering practice methods.

The authors contend that this milieu, and other factors, create high levels of vocational stress and may generate high levels of burnout. However there are mixed messages from the available information sources and to date there has been no research into this sizable and significant occupational group.

Although burnout and stress are separate concepts, it has been a commonly held belief that the cumulative effect of chronic stress often results in a condition known as burnout [33]. This has been particularly prevalent in the health care service industry [34]. If stress and burnout in the delivering of chiropractic care are at similar levels to that of other helping professions then accurate data, as opposed to anecdotal information, are required for a number of reasons.

First, burnout can negatively affect the chiropractic professional and in turn the quality of care delivered to the patient. Burnout has been implicated in poor patient outcomes in other caring professions $[11,12]$. It is, therefore, possible that higher burnout levels result in poorer clinical decisions and treatment applications with an increased incidence of adverse outcomes.

Second, Mertz et al. (2010) suggest that most nonpracticing chiropractors believed that the practice of chiropractic medicine was not a good career choice and would not recommend someone choosing chiropractic as a vocation [29]. Research has suggested that chiropractic colleges rely on practicing chiropractors as major recruiters of students [35]. Increasing levels of burnout in the chiropractic profession may impact on this avenue of student recruitment for chiropractic colleges.

Third, this is a preventable syndrome [36,37]. Early recognition and intervention have been shown to reduce the negative impact on individuals, families, communities and health resources [36,37]. Similar actions may be needed in the chiropractic profession. Finally, the impact of stress and burnout on health care professionals may have significant consequences also on the provider [38]. On a personal level this has included a depletion of emotional and physical resources, an increased likelihood of feelings of incompetence, a lack of achievement (negative self-image) and neglect of self, coupled with family and broader societal obligations [39]. It has also been implicated in higher levels of mental illness, substance abuse, absenteeism, reduced productivity and compromised patient care [6,10,19,39-43].

The authors contend that with such potentially serious and long-term consequences, this issue can no longer be left unexplored in the chiropractic profession.

\section{Purpose and objectives of the study}

The purpose of the intended study is to learn more about the levels of stress and burnout in the chiropractic profession. The specific objectives are to measure their prevalence and to compare those to levels previously identified and quantified in helping professions similar to the chiropractic profession.

\section{Methods/Design}

\section{Study population and sampling}

The authors intend to approach the appropriate chiropractic registration bodies with a request for assistance in distributing a mail out questionnaire to their membership. A pre-paid envelope with return address will be included. An alternative on-line survey option will also be made available.

For example, access to email listings of chiropractors is available for academic/educational purposes via a request through the State Board of Chiropractic Examiners, NJ. The investigators could request the email 
contact information of a randomized sample of licensed chiropractors from the State of New Jersey, State Board of Chiropractic Examiners, thus ensuring a systematic random sampling of the population of interest.

Subjects will include any Doctor of Chiropractic currently licensed to practice chiropractic and whom is at least 21 years old; with no limit on maximum age criteria.

Assuming a $60 \%$ return rate, the investigators will request the email contact information of a randomized sample of at least 500 licensed chiropractors in order to obtain sufficient numbers for the appropriate statistical analysis to be performed.

\section{Variables of interest and their rationale}

While the term "burnout" has become quite common in both research and practice, it has been ill defined historically. Initially, the term burnout was introduced by Freudenberger in the 1970's, and was used as an informal expression by lawyers, social workers, psychiatrists, teachers and hospice counsellors, to denote their gradual energy depletion and loss of motivation and commitment that was often associated with a wide array of other physical and mental symptoms [41,44].

Maslach's (1982) definition of burnout is now the most influential and widely referenced [33]. It is described in their self-titled inventory (Maslach Burnout Inventory- MBI) as a psychological syndrome of emotional exhaustion (EE), depersonalization (DP), and reduced personal accomplishment (PA) that can occur among people who work with other people in some helping capacity. Here emotional exhaustion is seen to reduce a workers ability to provide support at a psychological level [45]. Depersonalization results in a negative and/or cynical attitude towards his or her client and/or work related responsibilities. The third aspect of burnout, reduced personal accomplishment, refers to the tendency to evaluate oneself negatively, such that one is no longer effective in working with clients and in fulfilling one's job responsibilities $[2,45]$. Their inventory has been shown to be both a reliable and valid tool in evaluating job burnout [2]. To date, the primary form of this instrument used to measure burnout among helping professionals is the MBI-HSS $[2,11,38,44,46]$. Three dimensions EE, DP and PA are rated on a 7-point likert scale (ranging from 0, "never" to 6, "every day"). Scores on each subscale are computed by summing the numeric responses. Permission to use the MBI-HSS will be obtained from Consulting Psychologists Press http:// www.mindgarden.com/products/mbi.htm.

Respondents will also be asked to complete a second questionnaire that contains demographic questions (including gender, age, income levels and absenteeism) and open-ended questions related to chiropractic-specific stressors, as previously found in the literature. Examples of these include issues such as poor public perception, professional-identity inconsistencies, philosophical dissonance, negative media coverage, workplace injury levels from unique physical demands, market competition from other manual therapists, student loan default rates in North America and threats to autonomy $[26,47,48]$.

\section{Data collection and management}

An email letter of solicitation will be send to the random sample of emails via a group email distribution. This letter of solicitation will be in the body of the email and contain a link to an online version of the Maslach Burnout Inventory-Human Services Survey (MBI-HSS) and a brief demographic questionnaire developed by the primary investigator. SURVEY MONKEY (Gold member) software will be the electronic medium used. The Consent to Participate page shall include the title and purpose of the project, procedures for the anonymous and voluntary nature of the survey and potential risks and benefits to participants. The participants will complete the surveys in a place of their choice (e.g., their office, home or place of work), which has access to a computer. The Principal Investigator (PI) will conduct his portion of the research at York College, 94-20 Guy R. Brewer Blvd, Jamaica, NY 11451.

All survey related data will be stored on a thumb drive, which will be stored in locked cabinet at the place of research. After a minimum of 3 years, the PI will destroy the information on the thumb drive.

\section{Analysis of data}

This study is conducted with an observational research design that will involve the use cross-sectional data collection as a means of establishing the prevalence of burnout among chiropractors and to examine its association with some potential risk factors.

The primary analysis will involve descriptive summary statistics (means, standard deviations) and inferential statistics (confidence intervals) for estimating the prevalence of burnout. The use of univariate analysis using $t-$ tests and chi-square statistic will be utilized to compare the rate of burnout with the factors under investigation. Chiropractic-specific stressors will be correlated using Pearson correlation. Moreover, the relationship between the dimensions of burnout and ratio-level demographic variables will be tested using bivariate Pearson correlational analyses. Spearman's rho analyses will we used for ordinal-level data. To control for possible confounding factors, a multiple logistic regression will be utilized with burnout as the dependent variable. 


\section{Ethical considerations}

Research ethics and ethics approval will be sought from the principal investigators academic institution at the School of Health \& Behavioral Sciences, CUNY - York College, New York, United States of America. All responses will be kept completely confidential and investigator(s) will be blinded to response and subject identity connectors.

\section{Discussion}

\section{Summary of proposed study, need for the study and benefits of the study}

Chiropractors are significant members of the health care community. Past studies have shown that the health care profession population experiences high levels of stress and burnout. Previous studies have identified ameliorable factors, which can result in the implementation of effective interventions with outcomes that include improved levels of patient care and practitioner health measures. No such exploration has been offered in the chiropractic profession; consequently an evidence-based intervention is not possible. The authors contend that now is the time.

\section{Abbreviations}

U.S.: United States: EE: Emotional exhaustion; DP: Depersonalization; PA: Personal accomplishment; PI: Principle investigator.

\section{Author details}

'Department of Health Professions, CUNY York College, 94 - 20 Guy R. Brewer Blvd, Jamaica, NY 11451, USA. 235 Maroondah Highway, Lilydale 3140, Australia

\section{Authors' contributions}

SW is the PI of the proposed study, and the original proposal author. SI added content expertise and editorial modifications. Both authors read and approve the final version of the manuscript.

\section{Competing interests}

The authors declare that they have no competing interests.

Received: 4 July 2011 Accepted: 27 February 2012

Published: 27 February 2012

\section{References}

1. Grembowski D, Paschane D, Diehr P, Katon W, Martin D, Patrick DL: Managed care, physician job satisfaction, and the quality of primary care. J Gen Intern Med 2005, 20(3):271-277.

2. Maslach C, Jackson S, Leiter M: Maslach Burnout Inventory Manual. 3 edition. California: Consulting Psychologist Press; 1996.

3. Gunn SM, Woolfolk M, Maxson B: Dentists: satisfaction and attitudes on the future. J Am Coll Dent 1990, 57(1):12-15.

4. Humphris G: A review of burnout in dentists. Dent Update 1998, 25(9):392-396.

5. Te Brake H, Bouman AM, Gorter R, Hoogstraten J, Eijkman M: Professional burnout and work engagement among dentists. Eur J Oral Sci 2007, 115(3):180-185.

6. Piko BF: Burnout, role conflict, job satisfaction and psychosocial health among Hungarian health care staff: a questionnaire survey. Int I Nurs Stud 2006, 43(3):311-318
7. Kumar S, Fischer J, Robinson E, Hatcher S, Bhagat RN: Burnout and job satisfaction in New Zealand psychiatrists: A national study. Int I SOC Psychiatry 2007, 53(4):306-316.

8. Maslach C, Schaufeli WB, Leiter MP: Job burnout. Annu Rev Psychol 2001, 52:397-422.

9. Ilhan MN, Durukan E, Taner E, Maral I, Bumin MA: Burnout and its correlates among nursing staff: questionnaire survey. J Adv Nurs 2008 61(1):100-106.

10. Wandling BJ, Smith BS: Burnout in orthopaedic physical therapists. $J$ Orthop Sports Phys Ther 1997, 26(3):124-130.

11. Balogun JA, Titiloye V, Balogun A, Oyeyemi A, Katz J: Prevalence and determinants of burnout among physical and occupational therapists. $J$ Allied Health 2002, 31(3):131-139.

12. Donohoe E, Nawawi A, Wilker L, Schindler T, Jette DU: Factors associated with burnout of physical therapists in Massachusetts rehabilitation hospitals. Phys Ther 1993, 73(11):756-61, 750. 6; discussion.

13. Li Calzi S, Farinelli M, Ercolani M, Alianti M, Manigrasso V, Taroni AM: Physical rehabilitation and burnout: different aspects of the syndrome and comparison between healthcare professionals involved. Eura Medicophys 2006, 42(1):27-36.

14. Ogiwara $\mathrm{S}$, Hayashi $\mathrm{H}$ : Burnout amongst physiotherapists in Ishikawa Prefecture. J Phys Ther Sci 2002, 14(1):7-13.

15. Schuster ND, Nelson DL, Quisling C: Burnout among physical therapists. Phys Ther 1984, 64(3):299-303.

16. Painter J, Akroyd D, Elliot S, Adam RD: Burnout among occupational therapists. Occup Ther Health Care 2003, 17(1):63-78.

17. Meade I, Brown T, Trevan-Hawke J: Female and male occupational therapists: a comparison of their job satisfaction level. Aust Occup Ther J 2005, 52:136-148.

18. Rogers JC, Dodson SC: Burnout in occupational therapists. Am J Occup Ther 1988, 42(12):787-792.

19. Wolfe GA: Burnout of therapists: inevitable or preventable? Phys Ther 1981, 61(7):1046-1050.

20. Leiter MP, Maslach C: Burnout and health. In Handbook of health psychology. Edited by: Baum A, Revenson TA, Singer JE. Mahwah, NJ: Erlbaum; 2001:415-426.

21. Ahola K, Hakanen J: Job strain, burnout, and depressive symptoms: a prospective study among dentists. J Affect Disord 2007, 104(1-3):103-110.

22. Demerouti $E$, Bakker AB, Nachreiner F, Schaufeli WB: The job demandsresources model of burnout. J Appl Psychol 2001, 86(3):499-512.

23. Pavlakis A, Raftopoulos V, Theodorou M: Burnout syndrome in Cypriot physiotherapists: a national survey. BMC Health Serv Res 2010, 10:63.

24. Occupational outlook handbook, 2010-11 edition, chiropractors. 2009, [Internet]; Available from: http://www.bls.gov/oco/ocos071.htm..

25. Tindle HA, Davis RB, Phillips RS, Eisenberg DM: Trends in use of complementary and alternative medicine by US adults: 1997-2002. Altern Ther Health Med 2005, 11(1):42-49.

26. Editoral Staff: Gullop poll: Americans have low opinion of chiropractors' honesty and ethics. Dyn Chiropr 2007, 25(03)[http://dynamicchiropractic. $\mathrm{com} / \mathrm{mpacms} / \mathrm{dc} /$ article. .php?id=52038].

27. Careercast.com releases 2011 stressful job report. 2011, [Internet]; April 19, Available from: http://green.tmcnet.com/news/2011/04/19/5454753.htm.

28. Foreman SM, Stahl MJ: The attrition rate of licensed chiropractors in California: an exploratory ecological investigation of time-trend data. Chiropr Osteopat 2010, 18:24

29. Mirtz TA, Hebert JJ, Wyatt LH: Attitudes of non-practicing chiropractors: a pilot survey concerning factors related to attrition. Chiropr Osteopat 2010, 18:29.

30. Garte SH: The cost of caring - staying on the fire: The chiropractor's guide to burnout. ICA Rev 1987, 43(4):9-13.

31. Simon S: Primary prevention for career burnout: building resilience. Dynamic Chiropractic 2008, 26(13):1-10.

32. Extinguishing job burnout. 2010, [Internet]; Available from: http://www. acatoday.org/content_css.cfm?CID=2283..

33. Schaufeli W, Enzmann D: The burnout companion to study and practice: $A$ critical analysis London: Taylor \& Francis; 1998.

34. Felton JS: Burnout as a clinical entity-its importance in health care workers. Occup Med (Lond) 1998, 48(4):237-250.

35. Coulter I, Adams A, Coggan P, Wilkes M, Gonyea M: A comparative study of chiropractic and medical education. Altern Ther Health Med 1998, 4(5):64-75. 
36. Balch CM, Shanafelt T: Combating stress and burnout in surgical practice: a review. Thorac Surg Clin 2011, 21(3):417-430.

37. Ybema JF, Evers MS, van Scheppingen AR: A longitudinal study on the effects of health policy in organizations on job satisfaction, burnout, and sickness absence. J Occup Environ Med 2011, 53(11):1251-1257.

38. Maslach C, Florian V: Burnout, job setting, and self-evaluation among rehabilitation counsellors. Rehabil Psychology 1988, 33:85-93.

39. Blust L: Health professional burnout: Part I \#167. J Palliative Med 2009, 12(7):639-640.

40. Dyrbye LN, Thomas MR, Massie FS, Power DV, Eacker A, Harper W, et al: Burnout and suicidal ideation among U.S. medical students. Ann Intern Med 2008, 149(5):334-341.

41. Freudenberger HJ: Staff burn-out. J Soc Issues 1974, 30:159-165.

42. Kompier MAJ, Marcelissen FHG: Handbook work stress Amsterdam: NIA; 1990.

43. Maslach C: Burned-out. Human Behavior 1976, 5(9):16-22.

44. Schaufeli WB: Past performance and future perspectives of burnout research. SA J Ind Psychol 2003, 29(4):1-15

45. In Evaluating Stress: A book of resources. Edited by: Zalaquett CP, Wood RJ. Lanham, Md., 1997:

46. Maslach C, Jackson SE: The measurement of experienced burnout. J Occup Behav 1981, 2(2):99-113.

47. Copper R, McKee HJ: Chiropractic in the United States: trends and issues. Milbank Q 2003, 81(1):107-138.

48. Foreman SM, Stahl MJ: Chiropractors disciplined by a state chiropractic board and a comparison with disciplined medical physicians. J Manipulative Physiol Ther 2004, 27(7):472-477.

doi:10.1186/2045-709X-20-4

Cite this article as: Williams and Innes: Burnout among chiropractic practitioners: real or imagined an exploratory study protocol.

Chiropractic \& Manual Therapies 2012 20:4

\section{Submit your next manuscript to BioMed Central and take full advantage of:}

- Convenient online submission

- Thorough peer review

- No space constraints or color figure charges

- Immediate publication on acceptance

- Inclusion in PubMed, CAS, Scopus and Google Scholar

- Research which is freely available for redistribution

Submit your manuscript at www.biomedcentral.com/submit 